\title{
Foucault, do retorno da linguagem ao dizer-verdadeiro
}

\author{
Foucault, from the language return to the true saying
}

\section{José Ternes}

Professor titular, Pontifícia Universidade Católica de Goiás (PUC Goiás), Goiânia, GO - Brasil, e-mail: josternes@hotmail.com

\section{Resumo}

A episteme moderna, segundo Foucault, significou uma profunda transformação da cultura ocidental a partir dos começos do século XIX. A linguagem, então, recebeu novo estatuto, com densidade e intensidade próprias. Ela efetivamente retornou, dado que, durante dois séculos, se limitara à pura discursividade, ao desdobramento infinito dos signos. A expressão a linguagem fala dá o tom dessa transformação, com destaque especial para a literatura. Talvez se possa encontrar entre essa experiência e aquela descrita em A hermenêutica do sujeito sob a denominação parrhesia algo em comum. Atitudes radicais que demandam o desaparecimento do eu que fala, o retraimento/apagamento do mestre no dizer-verdadeiro.

Palavras-chave: Sujeito. Verdade. Linguagem. Parrhesia.

\section{Abstract}

According to Foucault, since the beginning of the 19th century the modern episteme meant a deep change on the occidental culture. The language, then, gets a new statute with its 
own density and intensity. It definitely returns given that during the past two centuries it had been limited to sole discursivity, to the unfolding of infinite symbols. The expression the language speaks gives the tone of this change that especially features the literature. One may find something in common between this experience and that one described in The hermeneutics of the subject under the denomination of parrhesia - the radical attitudes that demand the disappearance of the speaking self, the shrinking/erasing of the master of the true saying.

Keywords: Subject. Truth. Language. Parrhesia.

O leitor de Foucault percebe logo o que está em jogo: de um lado, a modernidade; de outro, a antiguidade greco-romana. Les mots et les choses. Le souci de soi. Observando, no entanto, que essas demarcações, bastante claras na obra do filósofo, cronologicamente bem definidas, encontram um momento, talvez único, de confluência, ou de embaralhamento. Refiro-me a La pensée du dehors. Eis o que lemos logo no começo: "a verdade grega foi outrora abalada por esta única afirmação: Eu minto. Eu falo põe à prova toda a ficção moderna" (FOUCAULT, 1986, p. 9).

O filósofo não se demora no paradoxo epimenídico, segundo ele, facilmente contornado. Em última instância, mentira ou não, "o sujeito que fala é o mesmo que aquele de que ele fala" (FOUCAULT, 1986). Importa a Foucault, nesse texto escrito em 1966 (a data conta, aqui), a segunda afirmação, je parle. Importa-lhe, não a Grécia Antiga, mas a modernidade. Aparentemente, também nenhum problema mais sério à vista. Eu falo e eu digo que falo parecem compor-se em perfeita harmonia. Todo perigo de erro, todo paradoxo, exorcizado. "É, portanto, verdadeiro, inegavelmente verdadeiro que eu falo quando digo que falo" (FOUCAULT, 1986, p. 10). Garantia do eu, do sujeito falante. Garantia do falar.

Contudo, Foucault logo suspeita: talvez "as coisas não fossem assim tão simples" (FOUCAULT, 1986). Permanecer naquela primeira impressão seria esquecer os resultados fundamentais dos estudos 
arqueológicos ainda palpitantes. Seria olvidar que, na modernidade, o sujeito aparece, sem dúvida, como figura nuclear, o que sabe, o que pode, o que fala, mas, também, finito, sempre às voltas com o desconhecimento, o assujeitamento, o silêncio, a mudez.

Eu falo, de fato, se refere a um discurso que, em lhe oferecendo um objeto, lhe serviria de suporte. Ora, esse discurso falta; o eu falo não instala sua soberania senão na ausência de qualquer outra linguagem; o discurso de que eu falo não preexiste à nudez enunciada no momento em que digo $e u$ falo; e desaparece no instante mesmo em que me calo. Toda possibilidade de linguagem é aqui abortada (desséchée) pela transitividade em que ela se realiza. $\mathrm{O}$ deserto a circunda. Em que extrema delicadeza, em que limite (pointe) singular e sutil se recolheria uma linguagem que quisesse se reconstituir (ressaisir) na forma despojada do eu falo? A não ser que justamente o vazio em que se manifesta a fragilidade sem conteúdo do eu falo seja uma abertura absoluta por onde a linguagem pode se expandir infinitamente, enquanto o sujeito - o eu que fala - se despedaça, se dispersa e se espalha até desaparecer nesse espaço nu (FOUCAULT, 1986, p. 11).

Essa experiência, novidade na história do pensamento ocidental, mesmo reconhecendo sua afinidade com a Renascença, Foucault a reconhece em Maurice Blanchot. La pensée du dehors fora a justa homenagem, não apenas a um amigo, mas, acima de tudo, a um pensamento singular. $\mathrm{O}$ espaço, porém, da possibilidade dessa experiência encontra em Les mots et les choses a sua arqueologia. E o nome, a expressão inventada para esse acontecimento, me parece bastante feliz: o retorno da linguagem (FOUCAULT, 1966).

Se isolarmos, em Les mots et les choses, a questão linguagem, poderemos assinalar três momentos bem distintos: o da prosa do mundo, o do desaparecimento da linguagem na pura discursividade e, finalmente, o de seu retorno na virada para o século XIX.

Não me parece necessário expor, com maiores detalhes, em que consiste cada um desses momentos. Ressaltaria apenas que, nas histórias arqueológicas, especialmente em Histoire de la folie e em Les mots et les choses, descreve-se, aproximadamente, uma mesma trajetória (já Naissance de la clinique começa com a Idade Clássica e Nietzsche, Marx e Freud nos leva, da modernidade, diretamente à Renascença). História 
cuja síntese poderia ser, aproximadamente, a seguinte: houve uma vez uma experiência tal em que o mundo todo era prosa, fala desenfreada dos loucos em suas naves sem destino, movimento interminável dos seres sobre si mesmos, em um jogo infinito de similitudes, "a terra repetindo o céu, os rostos mirando-se nas estrelas e a erva envolvendo nas suas hastes os segredos que serviam ao homem" (FOUCAULT, 1966, p. 32).

Houve, pois, uma época em que bem se poderia falar em ser da linguagem. Experiência, talvez, impossível de ser narrada com alguma precisão. Como observamos no Prefácio a Les mots et les choses, escapa-nos por entre os dedos. Veja-se o texto de Borges. Sua leitura "perturba todas as familiaridades do pensamento - do nosso: daquele que tem nossa idade e geografia" (FOUCAULT, 1966, p. 7). Houve, no entanto, essa experiência. E experiência logo desaparece para dar lugar a outra, a outras. Assim, a da loucura louca, aos poucos, perde espaço para a sage folie. Erasmo, com sua crítica, no centro; assim, o espaço geral da similitude. Apaga-se, em pouco tempo, a escrita das coisas.

E o Ocidente assiste ao desdobramento de uma segunda experiência. Sua singularidade foi assim definida por Heidegger: "o ser do existente é (agora) procurado e encontrado na condição de representado do existente" (HEIDEGGER, 1972, p. 82). Foucault parece ter levado a sério essa tese de uma idade da representção. ${ }^{1}$ Suas histórias mostram, à exaustão, o que isso significa. Entre as mais eloquentes, para nossa ilustração, destacaria esta passagem sobre Cervantes:

as palavras erram ao acaso, sem conteúdo, sem semelhança para preenchê-las; não marcam mais as coisas; dormem entre as folhas dos livros, no meio da poeira [...]. A escrita e as coisas não se assemelham mais. Entre elas, Dom Quixote vagueia ao sabor da aventura (FOUCAULT, 1966, p. 61-62).

Ocorre o mesmo com todas as figuras do mundo, tristes ou não, pois é a episteme toda que se encontra, naquele começo do século XVII, modificada em sua disposição fundamental. O espaço onde as coisas

Trata-se de uma tese polêmica. Não cabe, aqui, entrar na discussão. 0 livro de Vera Portocarrero, As ciências da vida: de Canguilhem a Foucault, publicado pela Fiocruz em 2009, nos fornece algumas pistas. 
se ordenam para o saber é outro. Ou, talvez, já não sejam mais as coisas que se ordenam, mas apenas as suas imagens. As coisas, essas foram reduzidas ao silêncio. Cala-se o louco, no indiferenciado Grande Internamento. Calam-se os vivos, na planura dos jardins botânicos e dos gabinetes de História Natural. Calam-se os corpos doentes, vez que sua verdade se elucida alhures, no jardim das espécies. Mas, fundamentalmente, desaparece a linguagem. Seu ser dá lugar ao vazio do discurso. Teria havido, pois, uma época em que a linguagem fora elidida no interior da cultura ocidental. Ou, quem sabe, perdera as condições mesmas de existência. As consequências desse acontecimento são enormes. E não se trata, aqui, de estimar-lhes o peso. O certo é que também essa experiência se esgota. Os últimos anos do século XVIII testemunham o ocaso do momento cartesiano, assumindo os riscos do discurso do Foucault dos anos 80. Canguilhem (1967) parece dizer tudo com essa outra expressão: l'épuisément du cogito. Ao contrário do que muitos afirmavam, não se trata da morte do homem, mas do cansaço de um pensamento, o cartesiano.

Eis-nos, portanto, às voltas com uma terceira experiência, e cujas condições de possibilidade aparecem, em Les mots et les choses, inicialmente, na forma negativa: fora preciso, primeiro, que toda aquela configuração epistemológica se modificasse; fora preciso que desaparecesse o solo no qual os seres poderiam se ordenar, e este, sabemos, era a natureza mesma; fora preciso elidir a natureza; fora preciso, enfim, contornar a representação. Diagnosticar o modo próprio de ser da modernidade significa, pois, primeiramente, investigar os limites, as fronteiras, de seu aparecimento. A arqueologia do presente demanda descrever mais do que o apenas presente. Impõe, acima de tudo, assinalar as transformações necessárias para que algo como a idade da história se estruturasse. A modernidade se esclarece, pois, na morte do que ela não poderia ter sido, especialmente na ruína de seu não passado, o cogito.

Impossível delinear, em poucos traços, o estatuto da nova episteme. $\mathrm{O}$ arqueólogo costuma fazer isso convocando testemunhas. Já vimos quais se constituíam em signos da Idade Clássica. Na modernidade, elas comparecem em número bem maior, mas em cada texto pode-se 
também apontar as indispensáveis. É o caso de Bichat e Broussais em Naissance de la clinique. É o caso de Esquirol, de Pinel, de Freud em Histoire de la folie. É o caso de Kant, Ricardo, Cuvier, Sade, Nietzsche em Les mots et les choses. Com isso pode-se ver que conhecer é outra coisa que a constituição do quadro dos seres. Trata-se, agora, de assinalar o nascimento e a morte do que há para pensar.

De todos os objetos, mesmo os aparentemente incorruptíveis do mundo físico, é preciso assinalar o lugar de sua formação e o de sua deformação. Todos os objetos são constitutiva e incontornavelmente históricos, e conhecer nada mais será que descrever a sua história. Entre tantos, um chama atenção especial: a linguagem. Ao contrário da novidade essencial de todos os outros, pois não temos notícias, no passado, de algo que se lhes avizinhe, o acontecimento linguagem é apresentado, em Les mots et les choses, de forma predicativa: o retorno da linguagem. Seria bastante estranho falarmos em retorno da vida, do trabalho, do homem. Tenho dúvidas, mesmo, se se deveria manter a expressão quando se trata de empiricidades como filologia, linguística e gramática histórica. Quer dizer, quando se faz da linguagem objeto. Em todo caso, Foucault parece considerar fundamental o fato de as palavras, na passagem para o século XIX, reencontrarem "sua velha, sua enigmática espessura (FOUCAULT, 1966). Logo, porém, assinala o paradoxo: o retorno vem estreitamente associado à dispersão. A unidade da linguagem, visível na Idade Clássica, desaparece como que numa região de sombras. "Destacada da representação, a linguagem doravante não mais existe, e até hoje ainda, senão de um modo disperso" (FOUCAULT, 1966, p. 315). Associação decisiva: enquanto o saber clássico da linguagem repousava inteiro sobre o a priori histórico da Gramática Geral, agora nos deparamos com possibilidades várias:

para os filólogos, as palavras são como tantos objetos constituídos e depositados pela história; para os que querem formalizar, a linguagem deve despojar-se de seu conteúdo concreto e só deixar aparecer as formas universalmente válidas do discurso; se se quer interpretar, então as palavras tornam-se texto a ser fraturado para que se possa ver emergir, em plena luz, esse outro sentido que ocultam; ocorre enfim à linguagem 
surgir por si mesma num ato de escrever que não designa nada mais que ele próprio( FOUCAULT, 1966, p. 315).

Esqueçamos as primeiras três possibilidades, a filologia, a lógica, a hermenêutica. Fixemo-nos, brevemente, na quarta, no fato de a linguagem poder surgir por si mesma.

Esse acontecimento, tardio em relação aos outros, teria a ver, antes de tudo, com Nietzsche. Fora ele "o primeiro a aproximar a tarefa filosófica de uma reflexão radical sobre a linguagem" (FOUCAULT, 1966, p. 316). Trata-se, fundamentalmente, de responder à questão: quem fala? A resposta do filólogo já nos é bastante familiar: é preciso verificar quem "detém a palavra" (FOUCAULT, 1966, p. 316). Um acontecimento político, portanto. Foucault, no entanto, parece pouco à vontade com a resposta nietzscheana. Coloca logo em cena outra figura: Mallarmé. Este "responde e não cessa de retomar sua resposta, dizendo que o que fala é, em sua solidão, em sua vibração frágil, em seu nada, a própria palavra - não o sentido da palavra, mas seu ser enigmático e precário" (FOUCAULT, 1966, p. 317).

Eis o espaço insinuado para a discussão, aqui, mas que Foucault não explora naquele começo de O homem e seus duplos. Mostra-se, mesmo, bastante enigmático e reticente. Les mots et les choses é, no entanto, texto indispensável para a ocasião. Descreve, como já assinalamos, as condições de possibilidade do retorno da linguagem. O que não é pouco.

Sabemos agora donde nos vêm essas questões. Elas tornaram-se possíveis pelo fato de que, no começo do século XIX, estando a lei do discurso destacada da representação, o ser da linguagem achou-se como que fragmentado; mas elas se tornaram necessárias quando, com Nietzsche, com Mallarmé, o pensamento foi reconduzido, e violentamente, para a própria linguagem, para seu ser único e difícil (FOUCAULT, 1966, p. 317).

Textos menores do filósofo, contemporâneos a Les mots et les choses, parecem prestar-se melhor para o tema. E o que aparece em primeiro plano é a literatura. Um modo de ser singular da linguagem, um acontecimento recente, sem parentesco com a "obra de linguagem" 
(FOUCAULT, 1964) ${ }^{2}$ de épocas anteriores. Acontecimento recente e raro, também. Uma dobra, poderíamos dizer, da episteme moderna. Difícil mostrar por que o interesse de Foucault pela literatura foi tão efêmero. Alguns anos, somente. A raridade apenas, no entanto, não o justificaria, pois, em todas as suas histórias, foi ela o seu objeto, aqueles pensamentos-limite que, de um lado, atestam o esgotamento de um e, de outro, prenunciam, já, a aurora de outro pensamento.

Importa, no entanto, sabermos que houve um interesse intenso pela literatura, ainda que por breve momento. Onde encontrar os registros desse interesse? Antes de tudo, em Les mots et les choses, como já lembramos. Trata-se, com efeito, do texto teórico por excelência acerca do espaço que torna o ser da linguagem pensável. Mas, os outros dois textos arqueológicos, cronologicamente muito próximos, Histoire de la folie e Naissance de la clinique, merecem nossa atenção. Não é a literatura o seu objeto, claro. Mas, acredito, também não é unicamente o seu "complemento", 3 caso com isso se insinue uma importância menor nas pesquisas arqueológicas. Roberto Machado (2000) mostra, com todo o seu rigor e erudição, que loucura e morte são temas que ultrapassam as fronteiras dos saberes nos quais aparentemente encontram seu lugar na modernidade. Dever-se-ia, então, buscar aí, na história da clínica e da psicanálise, elementos valiosos para a compreensão do ser mesmo da literatura.

Por outro lado, como já observei, há os textos chamados, aqui, e provisoriamente, menores: entrevistas, pequenos artigos, breves tratados. São bem conhecidas as testemunhas aí invocadas: Sade, Raymond Roussel, Artaud, Bataille, Flaubert, Mallarmé, Klossowski, Blanchot, Magritte, Pierre Boulez, etc. Mas, principalmente, Nietzsche.

Em La pensée du dehors, Foucault nos oferece uma breve justificativa da eleição de algumas dessas testemunhas de modernidade absoluta:

2 Distinção encontrada na conferência apresentada em Bruxelas, em março de 1964, sob o título Linguagem e literatura. Sua tradução aparece como Anexo no livro de Roberto Machado: Foucault, a filosofia e a literatura. Rio de Janeiro: Zahar, 2000.

3 Roberto Machado, no referido livro (2000, p. 12 ), fala em "complemento". Todo o texto, a seguir, me parece contestar essa palavra

Rev. Filos., Aurora, Curitiba, v. 23, n. 32, p. 131-144, jan./jun. 2011 
em Nietzsche, quando ele descobre que toda metafísica do Ocidente está ligada não somente à sua gramática [...], mas àqueles que detêm o direito à fala; em Mallarmé [...], o movimento no qual desaparece aquele que fala; em Artaud, quando toda a linguagem discursiva é instada a se soltar na violência do corpo e do grito, e o pensamento, deixando a interioridade falaz da consciência, se torna energia material, sofrimento da carne, perseguição e dilaceramento do próprio sujeito; em Bataille, quando o pensamento, em vez de ser o discurso da contradição e do inconsciente, se torna o do limite, da subjetividade rompida, da transgressão; em Klossowski, com a experiência do duplo, da exterioridade dos simulacros, da multiplicação teatral e demente do Eu (FOUCAULT, 1986, p. 18-19).

Finalmente, claro, Blanchot, com o seu pensamento do fora (dehors) e noções correlatas, como atração e negligência.

Essa enumeração aberta de possibilidades da linguagem literária encontra-se reduzida, fundamentalmente, a três em "Linguagem e literatura":

se, portanto, tivéssemos que caracterizar o que é a literatura, teríamos a figura negativa da transgressão e do interdito, simbolizado por Sade, a figura da repetição contínua, a imagem do homem que desce ao túmulo com o crucifixo na mão, desse homem que só escreveu do além-túmulo, a figura da morte simbolizada por Chateaubriand, e, finalmente, a figura do simulacro. Figuras não diria negativas, mas sem nenhuma positividade, entre as quais, o ser da literatura me parece fundamentalmente disperso e despedaçado (FOUCAULT apud MACHADO, 2000, p. 149).

No entanto, lembra o filósofo, transgressão, morte e simulacro, signos fundamentais das obras de Sade, Chateaubriand e Proust, respectivamente, possivelmente ainda não nos deem o ser da literatura,

talvez nos falte ainda, para definir o que é literatura, algo de essencial. Em todo caso, há algo que ainda não dissemos e que, no entanto, é historicamente muito importante para saber o que é essa forma de linguagem que apareceu a partir do século XIX (FOUCAULT apud MACHADO, 2000, p. 149).

Esse algo essencial, essa forma de linguagem nova da modernidade, sem precedentes, somente se esclarece do interior da história, de uma 
certa história, a arqueologia do saber. O que Foucault ainda não dissera, a essa altura da conferência, o dirá em outras ocasiões, especialmente em Les mots et les choses. Foi o que, bem ou mal, tentamos apresentar desde o começo.

Mas o eu falo, dissera Foucault, "põe à prova toda a ficção moderna". O retorno da linguagem talvez não seja, então, um acontecimento sem consequências. Ao contrário, coloca ao eu sérias obrigações. A relação de figuras, absolutamente modernas, já traz também, de cada uma, o engajamento ou a atitude de modernidade esperada. Com Sade e com Bataille, a transgressão; com Chateaubriand, a morte; com Hölderlin, a ausência dos deuses, a ruína de todo fundamento; com Proust, o simulacro; com Blanchot, o despedaçamento do sujeito. Em última instância, espera-se uma conversão. O velho sujeito, o cogito, precisa, efetivamente morrer. No lugar dele, já vimos a dispersão. É o que podemos ver em um belo texto dedicado a Deleuze, "Arianne est pendue":

pensar antes as intensidades (e mais cedo) do que as qualidades e as quantidades; antes as profundidades do que os comprimentos e as larguras; antes os movimentos de individuação do que as espécies e os gêneros; e mil pequenos sujeitos larvários, mil pequenos eus larvários, mil passividades e pululações lá onde, ontem, reinava o sujeito soberano (FOUCAULT, 1994, p. 770).

A literatura parece, pois, ser o ápice dessa pululação infinita de sujeitos larvários. Experiência extrema de subjetividades despedaçadas. Haveria um momento, um lugar, em que poderiam elas se reencontrar? Delírio de quem acredita em identidades. Foucault pertence a outra dinastia. A da diferença. Se seguirmos o texto La pensée du dehors, deparamo-nos com duas dessas figuras fundadoras do pensamento ocidental, signos de uma história racional, Ulisses (e suas sereias) e Eurídice (e seu Orfeu). Imaginar um Ulisses não acorrentado, nos braços das sereias, ou uma Eurídice, perdição absoluta de Orfeu, demandaria uma reescrita da história. Demandaria sancionar, na história, o que lhe fora sempre negado: o trágico. Parece-me ser essa a lição fundamental da experiência literária moderna: o retorno do trágico. Se quisermos, o retorno da linguagem torna novamente 
possíveis experiências interditadas, experiências de vidas intensas. Experiências-limite, essas que Foucault reconhece em Bataille, em Blanchot e em alguns outros.

Talvez seja prematuro postular alguma afinidade dessa experiência "do fora" com outras experiências no passado. Foucault, mesmo, o parece insinuar. A mais conhecida talvez seja certa familiaridade entre nós, modernos, e o Renascimento. Nosso renascentismo poderia ser reconhecido em diversos traços comuns: no excesso das similitudes, das analogias, na hermenêutica como modo privilegiado de se constituir a verdade. Idades do comentário sem freio. Em ambas, a mesma constatação: tudo é possível, vez que, lá e cá, falta a garantia de um ponto de apoio minimamente confiável.

Contudo, Foucault também parece acenar para a hipótese contrária: já não seríamos nós, da idade do homem, nos reconhecendo (palavra discutível) no passado, mas este, de certa maneira, prefigurando o, ou se repetindo em um futuro. Histoire de la folie tornou-se exemplar: refiro-me a Le neveu de Rameau. O Sobrinho teria uma função bem precisa. Prefiguraria ou anteciparia o pensamento antropológico moderno por vir. Em Les mots et les choses, embora também se possa assinalar um interesse explícito nas continuidades, algumas figuras, situadas estrategicamente nos "limites da representação", testemunham uma inflexão epistemológica que, do interior ainda do solo epistemológico clássico, prenuncia o nascimento de saberes, ou objetos, absolutamente outros daqueles possíveis na ordem cartesiana. É o caso de A. Smith para a economia política; de Lamarck para a biologia; de Coeurdoux e William Jones para os estudos da linguagem. Outros livros, quer arqueológicos, quer já da genealogia do poder, convocam testemunhas bastante afins. Assim, nem a clínica anátomopatológica, em Naissance de la clinique, nem as instituições disciplinares modernas, em Surveiller et punir, nem mesmo a explosão discursiva do sexo, desde o século XIX, em La volonté du savoir seriam acontecimentos de uma única geografia, de uma cronologia de primeiro olhar.

Os cursos no Collège de France reforçam essa forma de história. Se acompanharmos as aulas de 1981-1982, sob o título L'herméneutique du sujet, constatam-se jogos conceituais muito próximos desses 
encontrados nos livros de Foucault. "Ascese", "hermenêutica", "conversão" o testemunham bem. Veja-se o destino singular de convserão. Atravessando séculos, presença insistente na história do Cristianismo, reaparece com faces distintas, mas igualmente marcantes, na modernidade. Poderíamos destacar duas. Engajamento político, de um lado: converter-se ao partido, à revolução; engajamento espiritual, de outro: "experiência-limite", com Blanchot; "experiência interior", com Bataille; "engajamento racionalista”, talvez, com Bachelard. Retorno da mística!

O que significaria, ainda, a palavra sujeito nessas experiências? Qual o estatuto do eu na cultura greco-romana? E na modernidade, a nossa? Em ambos os casos estamos longe, muito longe, do "momento cartesiano", onde o "eu penso" era garantia do "eu sou". Conhecemos a ironia de Foucault no texto O cogito e o impensado, em Les mots et les choses:

posso eu dizer, com efeito, que sou essa linguagem [...]? Posso eu dizer que sou esse trabalho $[\ldots]$ ? Posso eu dizer que sou essa vida [... ? Posso dizer tanto que sou quanto que não sou tudo isso; o cogito não conduz a uma afirmação do ser, mas abre justamente para toda uma série de interrogações onde o ser está em questão (FOUCAULT, 1966, p. 335).

Se hoje, ainda, se puder falar sujeito, não é a Descartes que devemos recorrer. Nem mesmo a Kant. Mas, como insinua a primeira conferência de $A$ verdade e as formas jurídicas, à história: "ver como se dá, através da história, a constituição de um sujeito que não é dado definitivamente [...], e que é a cada instante fundado e refundado pela história" (FOUCAULT, 1999, p. 10). Histórico, portanto, não caberia dizer propriamente sujeito, mas, talvez, subjetivação. $\mathrm{O}$ sujeito moderno aparece, ao lado da vida, dos valores e da linguagem, como resultado da luta entre nascimento e morte. Um rosto apenas, desenhado na areia, prestes sempre a desaparecer.

Sou e não sou talvez seja também a resposta mais adequada do sujeito de certa literatura greco-romana explorada por Foucault em Hermenêutica do sujeito. Aironia de Les mots et les choses pode, então, repetir-se nesse curso, mas em uma cronologia invertida. Sêneca, Marco Aurélio, Epicteto, Epicuro, entre outros, são as testemunhas de uma experiência pouco lembrada, ou mesmo esquecida, pela maioria dos historiadores. 
Olvidada, particularmente, pela certeza cartesiana. Tributário de uma leitura reducionista dos textos platônico-socráticos, o cartesianismo teria sido o signo da fortuna do preceito délfico gnôthi seautón ("conhece-te a ti mesmo") na história do pensamento ocidental e, negativamente, o da desqualificação filosófica de um outro preceito, segundo Foucault correlato a este, o "cuida de ti mesmo". Uma leitura outra do Alcibíades não apenas permitiria mostrar a contemporaneidade dos dois preceitos, mas, o que é fundamental, a ascendência do segundo sobre o primeiro.

Assim, a ironia de Foucault reaparece nos Cursos do Collège de France, com outras personagens, em um tempo verbal outro. Sêneca e seus contemporâneos compartilham outro solo epistemológico, forçando uma linguagem própria da arqueologia. Poderia eu, então, dizer que sou, quando penso? Hipótese absurda para uma época em que o eu não contava com outra caução que a do exercício, da ascese, da "conversão a si". Época, como a modernidade, em que, rigorosamente, o eu não existe, mas apenas processos, lutas, contra o mundo e contra si, para a sua constituição. Também na Idade de Ouro do cuidado de si, valem as palavras da primeira conferência de $A$ verdade e as formas jurídicas, lembradas há pouco: "seria interessante tentar ver como se dá, através da história, a constituição de um sujeito" (FOUCAULT, 1999, p. 10). Ver como se dá a constituição do discípulo. Qual o seu lugar, quais as suas obrigações na condição de discípulo. A importância do silêncio e da escuta. Mas, principalmente, ver como se dá a constituição do mestre, aquele credenciado para dizer a verdade. Donde lhe vem o status de parrhesiarca?

A oposição entre a parrhesia e o modelo platônico de filosofia, bem como sua contraposição ao momento cartesiano, presta-se para assinalar a singularidade da experiência greco-romana. Nem contemplação da verdade, nem sua posse. O dizer verdadeiro do mestre, no extremo, talvez não seja do mestre. No extremo, é ele tomado, como que arrebatado, constituído na palavra, no falar, no escrever, na "escrita de si". $\mathrm{Na}$ leitura (de si), acima de tudo. "Hermenêutica do sujeito".

Poderíamos apostar, assim, em um interessante encontro com o modo de ser da linguagem moderna, antes de uma identidade de um eu que fala, o seu despedaçamento, a sua dispersão em infinitas formas de subjetividade. 


\section{Referências}

CANGUILHEM, G. Mort de l'homme ou épuisement du Cogito? Critique, Paris, n. 242, p. 599-618, 1967.

FOUCAULT, M. Les mots et les choses. Paris: Gallimard, 1966.

FOUCAULT, M. La pensée du dehors. Paris: Fata Morgana, 1986.

FOUCAULT, M. Linguagem e literature. In: MACHADO, R. Foucault, a filosofia e a literatura. Rio de Janeiro: Zahar, 2000. p. 137-174.

HEIDEGGER, M. Holzwege. Frankfurt am Main: Vittorio Klostemann, 1972.

MACHADO, R. Foucault, a filosofia e a literatura. Rio de Janeiro: Zahar, 2000. PORTOCARRERO, V. As ciências da vida: de Canguilhem a Foucault. Rio de Janeiro: Fiocruz, 2009.

Recebido: 15/09/2010

Received: 09/15/2010

Aprovado: 02/12/2010

Approved: 12/02/2010 